\title{
RESEARCH
}

Open Access

\section{Evaluating the outcome of classic laminectomy surgery alone versus laminectomy with fixation surgery in patients with lumbar canal stenosis regarding improvement of pain and function}

\author{
Mohamed A. El Tabl ${ }^{1}$, Yasser B. El Sisi', Saeed E. Al Emam¹, Mohamed A. Hussen ${ }^{1}$ and Dalia S. Saif ${ }^{2 *}$ (DD
}

\begin{abstract}
Background: Management of lumbar canal stenosis should be started with conservative treatment and preferably with a multimodal approach, but in cases of severe pain with extensive neurogenic claudication symptoms, surgical intervention is indicated. This retrospective study targets to evaluate the outcome of classic laminectomy surgery alone versus laminectomy with fixation surgery in patients with lumbar canal stenosis regarding improvement of pain and function.

Methods: Data of 184 patients of the study groups were divided into group A (data from patients who underwent laminectomy and foraminotomy only) and group B (data from patients who underwent laminectomy and foraminotomy with spinal fixation). Preoperative, operative, postoperative (PO), and follow-up data were extracted and analyzed from files of patients fulfilling the inclusion criteria.

Results: Primary outcome was at least 50\% improvement of pain severity regarding numeric rating scale (NRS) and Oswestry disability index (ODI) score at 6-months PO compared to preoperative scores. Operative time was significantly longer in group B than group A. Immediate PO data regarding PO analgesic requirement, amount of wound drainage, and PO hospital stay showed non-significant difference between both groups. There was a statically significant improvement of EHL muscle strength regarding Odom's scoring in group B in which the success rate for pain improvement was $81.8 \%$ and for disability was $66.8 \%$. There were insignificant differences in patient's satisfaction to surgery with variable ages, a significant outcome in females and in patients with fewer levels of affection of both groups.

Conclusion: The present study reported the efficacy and safety of the laminectomy, foraminotomy, discectomy, and medial facetectomy with spinal fixation using trans-pedicular screws for management of patients with spinal canal stenosis.
\end{abstract}

Keywords: Lumbar spinal stenosis, Spinal fixation, Pain improvement, Disability improvement

\footnotetext{
*Correspondence: Sdalia30@gmail.com

2Physical Medicine, Rheumatology and Rehabilitation, Faculty of Medicine,

Menoufyia University, Shebeen El-Kom-Menoufia, Egypt

Full list of author information is available at the end of the article
}

\section{Springer Open}

(- The Author(s). 2020 Open Access This article is licensed under a Creative Commons Attribution 4.0 International License, which permits use, sharing, adaptation, distribution and reproduction in any medium or format, as long as you give appropriate credit to the original author(s) and the source, provide a link to the Creative Commons licence, and indicate if changes were made. The images or other third party material in this article are included in the article's Creative Commons licence, unless indicated otherwise in a credit line to the material. If material is not included in the article's Creative Commons licence and your intended use is not permitted by statutory regulation or exceeds the permitted use, you will need to obtain permission directly from the copyright holder. To view a copy of this licence, visit http://creativecommons.org/licenses/by/4.0/. 


\section{Introduction}

The most frequent causes of degenerative constrictions of the spinal canal are disk herniation and spinal canal stenosis (CS) [1]. CS is a condition where the neural structures are compressed in the narrowed spinal canal and often situated only within a single specific region of the spine, most frequently in the lumbar spine [2]. Degenerative disk bulging and facet overgrowth lead to lumbar lateral recess stenosis, which is a very common cause for lumbar radiculopathy in the elderly [3].

Spinal canal stenosis presents in a variety of forms; symptomatic lumbar canal stenosis (LCS) occurs in about $10 \%$ of population and cervical CS in $9 \%$ of subjects aged over 70 years [4]. With progress of health services, the patients' longevity expectations are increasing, so number of patients with LCS is steadily increasing [5].

Basically, management of LCS should be started with conservative treatment and preferably with a multimodal approach (medical treatment, bed rest, and physiotherapy), but in cases of severe pain with extensive neurogenic claudication symptoms, surgical interference is indicated [5]. Lumbar decompression surgery is a commonly used treatment for degenerative LCS [6]. Classic surgical treatment of LCS involves wide laminectomy, foraminotomy, discectomy, and medial facetectomy if needed [7]. However, decompression surgery can further destabilize a pathological motion segment [3], and some patients develop symptomatic spinal instability [6]. Spinal instability after simple decompression promoted the development of fusion technique [8].

\section{Objectives}

The present study aims to evaluate the outcome of classic laminectomy surgery alone versus laminectomy with fixation surgery in patients with lumbar canal stenosis regarding improvement of pain and function.

\section{Patients and methods}

Data of all patients with chronic refractory pain to conservative treatment for 6 weeks and who underwent surgical interference were collected at the Neurosurgery Department, Faculty of Medicine, Menofia University at the period from June 2016 to July 2018 and were followed-up throughout a period of 6 months. The present study includes data of patients with evident manifestations of LCS as sever claudicating pain, recurrent lumbar pain that was not relieved by conservative treatment.

Data of patients with infrequent pain, mild pain relieved spontaneously or by rest, peripheral neuropathy, diabetes mellitus, cardiac, hepatic or renal diseases, coagulopathy, and all cases of spinal instability were excluded from this study.

The present study involved patients' demographic and clinical data, full medical history concerning type, site, and radiation of pain, and precipitating and relieving factors, drug history by using a 0 to 4 points Likert scale with 0 , no medication; 1 , simple analgesics as oral nonsteroidal anti-inflammatory drugs (NAISD); 2, injectable NAISD analgesia; 3 , as needed opioid prescription medications; 4, scheduled opioid prescription medications were also evaluated at 3 and 6 months post-operative and considered one of the secondary outcome evaluation parameters.

Data of clinical examinations includes the following:

-Pain severity assessment of back and lower limb by using an 11-point numeric rating scale (NRS) with numbers from 0 to 10 where 0 indicates no pain and 10 indicates worst pain imaginable $[9,10]$.

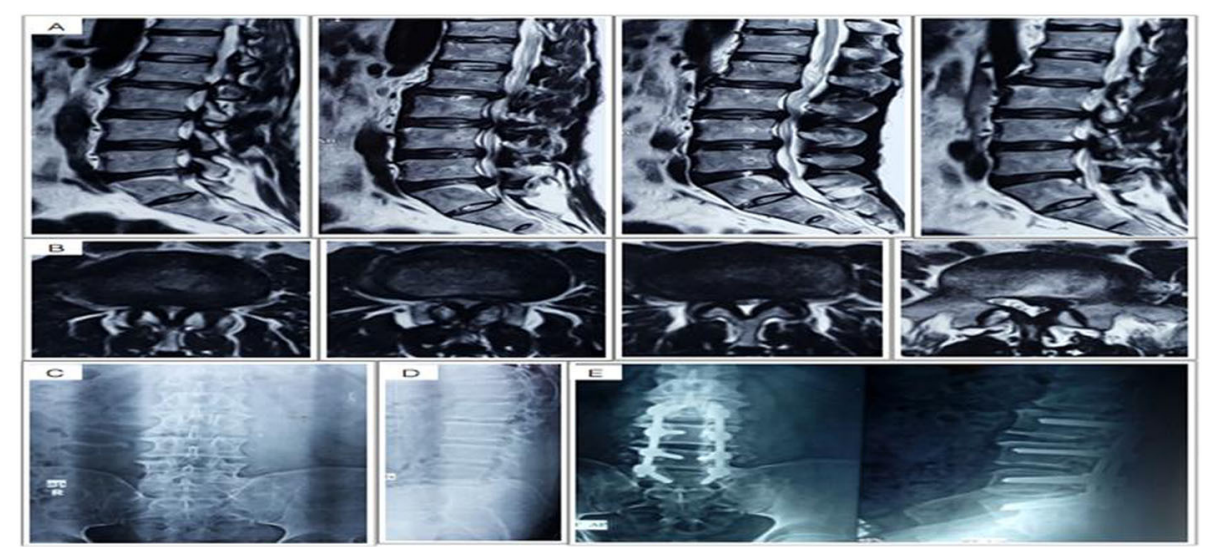

Fig. 1 Sagittal and axial T2WI MRI images ( $\mathbf{a}$ and $\mathbf{b}$ ) showed multiple level discogenic with ligamentum and bony stenosis. Preoperative radiographs [AP and lateral views] are normal with no spinal instability (c and $\mathbf{d}$ ). PO radiographs [AP and lateral views] showed 4 levels of conventional laminectomy with posterolateral fusion (e) 


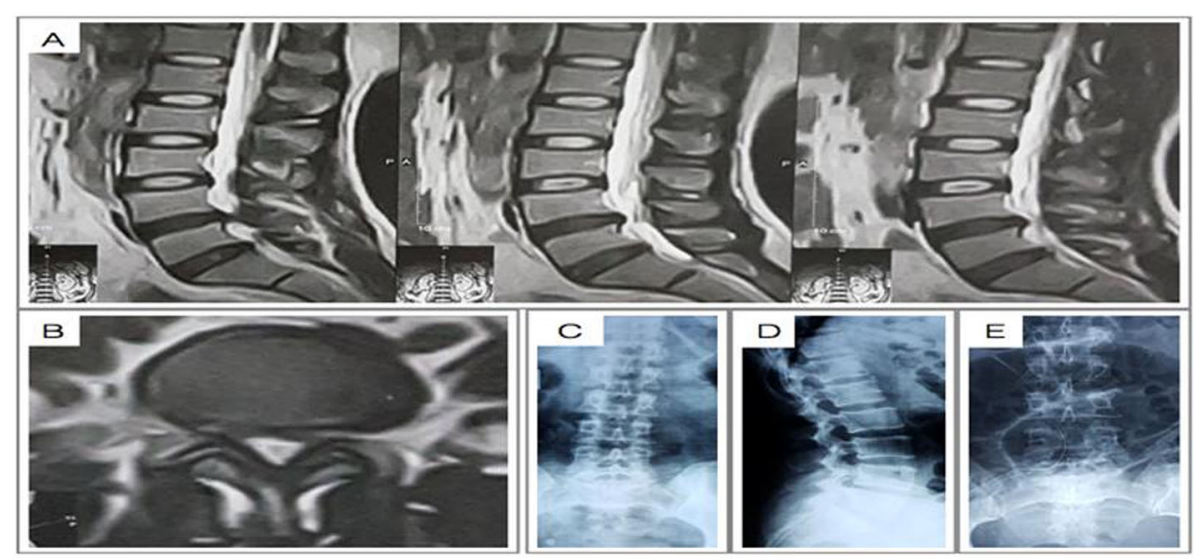

Fig. 2 Sagittal and axial T2WI MRI images (a and b) showed single level discogenic stenosis. Preoperative radiographs [AP and lateral views] are normal with no spinal instability (c and $\mathbf{d}$ ). Postoperative radiographs [AP and lateral views] showed single level conventional laminectomy (e)

-Assessment of disability secondary to pain by using the low back pain Oswestry disability index (ODI) that determines disability as minimal (0-20), moderate (20$40)$, severe (40-60), and ODI of $60-80$ indicated that patient is crippled and $80-100$ indicates that the patient is either bed-bound or exaggerating his or her symptoms [11-13]. Pain severity and ODI scores were assessed at 3 and 6 months post-operative and serves as primary outcome evaluation parameters.

-Assessment of the strength of EHL (extensor halucies longus) and feet dorsiflexor muscles at 3 and 6 months post-operative and considered one of the secondary outcome evaluation parameters by using the Oxford scale and was evaluated at 3 and 6 months postoperative and considered one of the secondary outcome evaluation parameters, with 5-strong, 4-partial resistance, 3-complete movement, 2-partial movement, 1 -contraction, and 0 -paralyzed $[14,15]$.
-Assessment of improvement was assessed by using Odom's criteria at 3 and 6 months post-operative and considered one of the secondary outcome evaluation parameters that included 4 grades: excellent-relief of all preoperative symptoms and all abnormal findings were improved; good-minimal persistence of preoperative symptoms and all abnormal findings were either unchanged or improved; fair-definite relief of some preoperative symptoms, while other symptoms were either unchanged or slightly improved; poor-all preoperative symptoms and signs were unchanged or exacerbated [16].

Patients' satisfaction with the procedure was assessed with a 4-point questionnaire, ranging from 4 points (very satisfied) to 1 point (very dissatisfied) at 3 and 6 months post-operative and considered one of the secondary outcome evaluation parameters.

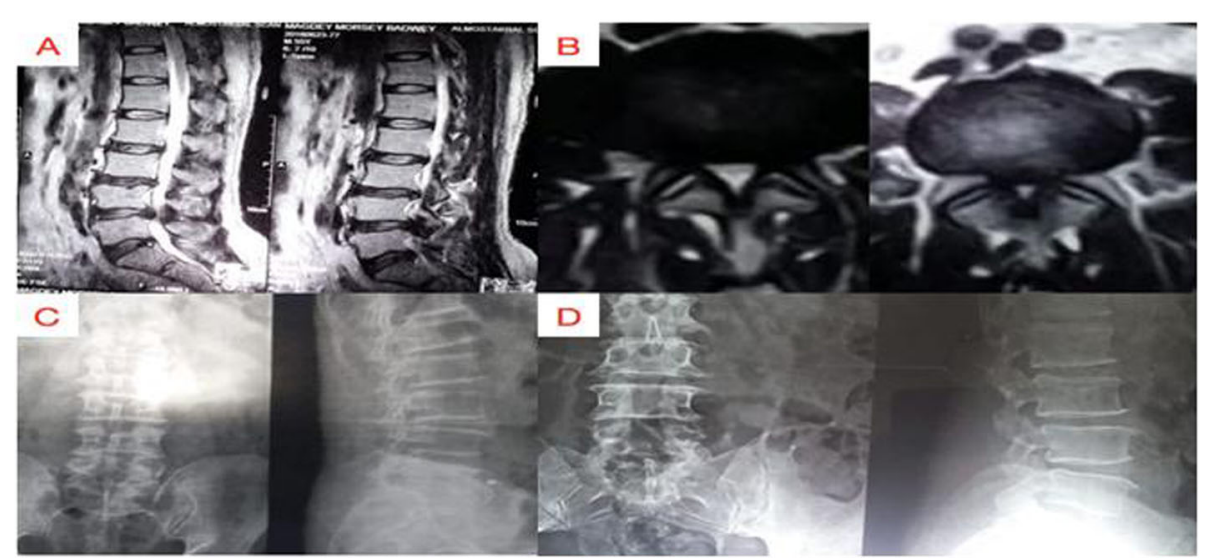

Fig. 3 Sagittal and axial T2WI MRI images are showing multiple level discogenic with ligamentum stenosis and spinal stenosis (a and $\mathbf{b})$. Preoperative radiograph [lateral and AP views] is showing no spinal instability (c). PO radiograph [AP and lateral views] showed double levels of conventional laminectomy 


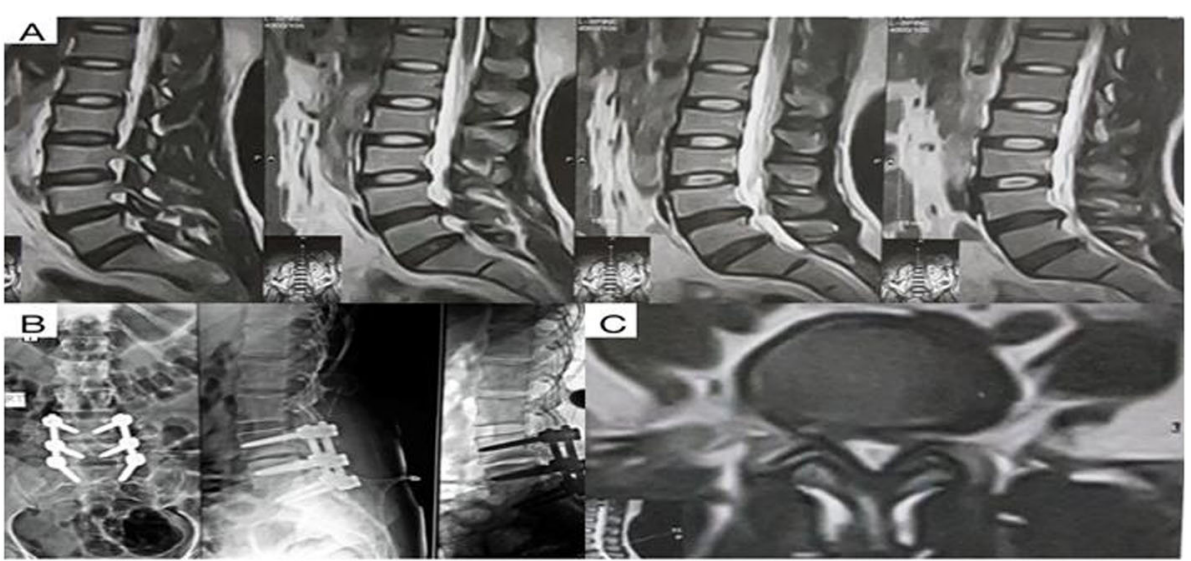

Fig. 4 Sagittal and axial T2WI MRI images are showing multiple level discogenic with ligamentum stenosis and spinal stenosis (a and c). PO radiograph (AP and lateral views) showed double levels of conventional laminectomy with fusion

Finally, data of radiological workup including X-ray imaging in anteroposterior (AP), lateral views and dynamic views (flexion-extension-oblique), and computerized tomography $(\mathrm{CT})$ lumbosacral spine then, magnetic resonance imaging (MRI) for lumbar spine also were obtained (Figs. 1, 2, 3, and 4).

Files of patients undertook wide laminectomy, foraminotomy, discectomy, and medial facetectomy without spinal fixation as a single therapeutic procedure were categorized as group A, while files of patients undertook wide laminectomy, foraminotomy, discectomy and medial facetectomy, and spinal fixation using transpedicular screws were categorized as group B. Both groups were equal in number.

\section{Statistical analysis}

The data collected were tabulated and analyzed by SPSS (statistical package for the social science software) statistical package version 23, 2015 on IBM compatible computer for Windows statistical package and were presented as mean $\pm \mathrm{SD}$, numbers, and percentages by using one-way ANOVA test, Student $t$ test and chisquare test $(X 2$ test). $P$ value $<0.05$ was considered statistically significant.

\section{Results}

The study included files of 215 patients; 31 files were excluded for not fulfilling the inclusion criteria and 184 files were divided into two equal groups to be analyzed.

Table 2 Patients satisfaction of surgery regarding ODOM in different ages and level of both groups

\begin{tabular}{|c|c|c|c|c|c|c|c|c|c|c|}
\hline \multirow[t]{4}{*}{ Gro } & \multirow{2}{*}{\multicolumn{3}{|c|}{$\begin{array}{l}\text { Group A }(n=92) \\
\text { ODOM }\end{array}$}} & $P$ value & \multicolumn{2}{|c|}{ Group B $(n=92)$} & \multicolumn{4}{|c|}{$P$ value } \\
\hline & & & & & & OD & & & & \\
\hline & \multicolumn{2}{|l|}{ Fair } & \multicolumn{2}{|c|}{ Good } & & \multicolumn{2}{|l|}{ Fair } & \multicolumn{2}{|c|}{ Good } & \\
\hline & No & $\%$ & No & $\%$ & & No & $\%$ & No & $\%$ & \\
\hline Age & & & & & & & & & & 0.397 \\
\hline $40-50$ & 4 & 44.4 & 5 & 55.5 & 0.357 & 5 & 25.0 & 15 & 75.0 & \\
\hline$>50-60$ & 25 & 46.2 & 29 & 53.7 & & 20 & 41.67 & 28 & 58.3 & \\
\hline$>60$ & 18 & 62.06 & 11 & 37.9 & & 10 & 41.67 & 14 & 58.3 & \\
\hline Gender & & & & & & & & & & $0.023^{*}$ \\
\hline Male & 33 & 63.5 & 19 & 36.5 & $0.01^{*}$ & 20 & 40 & 30 & 60 & \\
\hline Female & 10 & 25 & 30 & 75 & & 10 & 23.8 & 32 & 76.2 & \\
\hline Level & & & & & & & & & & $0.021^{*}$ \\
\hline One & 1 & 9.1 & 10 & 90.9 & $0.014^{*}$ & 0 & 0.0 & 8 & 100.0 & \\
\hline Two & 5 & 26.3 & 14 & 73.7 & & 2 & 15.4 & 11 & 84.6 & \\
\hline Three & 31 & 50.0 & 31 & 50.0 & & 29 & 40.8 & 42 & 59.2 & \\
\hline
\end{tabular}

This table shows insignificant differences in patient's satisfaction to surgery with variable ages, a significant outcome in females, and in patients with fewer levels of affection of both groups 
Table 1 Patients' enrollment data

\begin{tabular}{|c|c|c|c|c|c|}
\hline \multirow[t]{2}{*}{ Data } & & & \multirow{2}{*}{$\begin{array}{l}\text { Group A } \\
(n=92)\end{array}$} & \multirow{2}{*}{$\begin{array}{l}\text { Group B } \\
(n=92)\end{array}$} & \multirow{2}{*}{$\begin{array}{l}P \\
\text { value }\end{array}$} \\
\hline & & & & & \\
\hline \multirow[t]{4}{*}{ Age (years) } & & $40-50$ & $9(22.2 \%)$ & $20(26.7 \%)$ & $0.082 \mathrm{~S}$ \\
\hline & & $>50-60$ & $54(31.1 \%)$ & $48(33.3 \%)$ & \\
\hline & & $>60$ & $29(11.1 \%)$ & $24(8.9 \%)$ & \\
\hline & & Total & $59.6 \pm 7.2$ & $57.6 \pm 7.8$ & $0.073 \mathrm{~S}$ \\
\hline \multirow[t]{2}{*}{ Gender } & & Males & $58(63 \%)$ & $63(68.5 \%)$ & 0.437 \\
\hline & & Females & $34(37 \%)$ & $29(31.5 \%)$ & \\
\hline \multirow[t]{3}{*}{ BMl data } & & Weight (kg) & $84.3 \pm 6.8$ & $85.6 \pm 7.6$ & 0.227 \\
\hline & & Height $(\mathrm{cm})$ & $170.1 \pm 3.5$ & $170.4 \pm 3.4$ & 0.592 \\
\hline & & BMI $\left(\mathrm{kg} / \mathrm{m}^{2}\right)$ & $29.1 \pm 2$ & $29.5 \pm 2.3$ & 0.563 \\
\hline \multirow[t]{7}{*}{ Clinical findings } & Duration of LBP (months) & $<24$ & $20(21.7 \%)$ & $25(27.2 \%)$ & 0.674 \\
\hline & & $24-36$ & $58(63 \%)$ & $55(59.8 \%)$ & \\
\hline & & $>36$ & $14(15.3 \%)$ & $12(13 \%)$ & \\
\hline & & Total & $29.4 \pm 6.2$ & $28.1 \pm 7.7$ & 0.203 \\
\hline & Level & One level & $11(12 \%)$ & $8(8.7 \%)$ & 0.332 \\
\hline & & Two levels & 19 (20.7\%) & $13(14.1 \%)$ & \\
\hline & & Three levels & 62 (67.4\%) & 71 (77.2\%) & \\
\hline
\end{tabular}

Enrollment criteria for studied patients showed non-significant differences between both groups

There were significant differences between the two groups regarding age and insignificant differences regarding sex and level, and insignificant differences in patient's satisfaction to surgery with variable ages, a significant outcome in females compared to males who are heavy workers and due to their early return to activity with male-female ratio $5 / 4$, and significant differences in patients with fewer levels of affection of both groups (Tables 1, 2).

All surgical procedures were completed uneventfully, and despite the non-significant difference between both groups regarding operative time for discectomy and facetectomy; spinal fixation performed for patients of group $B$ required additional theater time, so total theater time was significantly longer in for patients of group B than those of group A. Amount of blood loss showed non-significant difference between patients of both groups and no patient required blood transfusion. All patients were transferred to the post-anesthetic care unit
(PACU) for immediate PO postoperative care and when patients had stable hemodynamics were transferred to the ward of the neurosurgery department (Table 3).

At ward, time till 1st request for analgesia, number of requests and total dose consumed showed nonsignificant difference between patients of both groups. Also, amount of wound drainage showed a nonsignificant difference between both groups. All patients were home-discharged after a median duration of PO hospital stay of 3 days, and mean duration of hospital stay showed non-significant difference between patients of both groups (Table 4).

There was a significant statically sustained continuous improvement of pain and disability scores throughout the period of follow-up (at 3 and 6 months postoperation) with more improvement at 6 months postsurgery (Figs. 5, 6). These findings were more superior in patients who went to spinal fixation surgery as manifested by the significantly lower pain and ODI scores,

Table 3 Operative data of studied patients

\begin{tabular}{|c|c|c|c|c|}
\hline \multirow[t]{2}{*}{ Group parameter } & & \multirow{2}{*}{$\begin{array}{l}\text { Group A } \\
(n=92)\end{array}$} & \multirow{2}{*}{$\begin{array}{l}\text { Group B } \\
(n=92)\end{array}$} & \multirow{2}{*}{$\begin{array}{l}P \\
\text { value }\end{array}$} \\
\hline & & & & \\
\hline \multirow[t]{3}{*}{ Theater time (min) } & Duration of surgical procedure (min) & $114 \pm 14.2$ & $110 \pm 18.7$ & 0.117 \\
\hline & Duration of adjuvant procedure (min) & 0 & $26.4 \pm 5.4$ & 0 \\
\hline & Total theater time (min) & $114 \pm 14.2$ & $136.5 \pm 19.6$ & 0.001 \\
\hline \multicolumn{2}{|c|}{ Amount of blood loss (cc) } & $438.9 \pm 103$ & $464.3 \pm 117.8$ & 0.121 \\
\hline
\end{tabular}

This table shows the non-significant difference between both groups regarding operative time for discectomy and facetectomy, the total theater time was significantly longer in patients of group B than those of group A. There was a non-significant difference between patients of both groups regarding the amount of blood loss and no patient required blood transfusion 
Table 4 Postoperative data of studied patients

\begin{tabular}{|c|c|c|c|c|c|}
\hline \multicolumn{3}{|l|}{ Group parameter } & \multirow{2}{*}{$\begin{array}{l}\text { Group A } \\
(n=92)\end{array}$} & \multirow{2}{*}{$\begin{array}{l}\text { Group B } \\
(n=92)\end{array}$} & \multirow{2}{*}{$\begin{array}{l}P \\
\text { value }\end{array}$} \\
\hline & & & & & \\
\hline \multirow[t]{6}{*}{ PACU pain data } & \multicolumn{2}{|c|}{ Time till request of 1st rescue analgesia (min) } & $65 \pm 10.7$ & $62.5 \pm 11.7$ & 0.126 \\
\hline & \multirow[t]{5}{*}{ Number of doses of rescue analgesia } & 1 & $12(13 \%)$ & $15(16.3 \%)$ & \multirow[t]{4}{*}{0.506} \\
\hline & & 2 & 49 (53.3\%) & $40(43.5 \%)$ & \\
\hline & & 3 & $22(23.9 \%)$ & $24(26.1 \%)$ & \\
\hline & & 4 & $9(9.8 \%)$ & $13(14.1 \%)$ & \\
\hline & & Mean & $2.3 \pm 0.8$ & $2.4 \pm 0.9$ & 0.498 \\
\hline \multicolumn{3}{|c|}{ Amount of wound drainage (cc) } & $160.6 \pm 50.8$ & $165.4 \pm 47.9$ & 0.673 \\
\hline \multicolumn{3}{|c|}{ Hospital stay (days) } & $3.4 \pm 1.1$ & $3.6 \pm 1.2$ & 0.159 \\
\hline
\end{tabular}

This table shows a non-significant difference between patients of both groups regarding the number of requests; total dose consumed and amount of wound drainage and non-significant difference regarding the mean duration of hospital stay between patients of both groups

throughout the period of follow-up of patients of group $\mathrm{B}$ compared to that of patients of group A. There were a significant statically higher success rate in group B versus group A regarding the reduction of pain and ODI scores (Table 5, Fig. 7).

There was a significant statically lower score for PO analgesic medications, in patients of group B than those of group A. Functionally, objective testing of all studied patients showed significant improvement regarding EHL muscle strength testing in comparison to their preoperative data with significantly superior outcome among patients of group B compared to group A. As regards patients' evaluation of improvement according to Odom's criteria, 50 patients $(27.2 \%)$ found the improvement was excellent, 98 patients (53.3\%) found it good, 24 patients (13\%) found the improvement was fair, and 12 patients (6.5\%) found it poor with a significantly higher frequency of patients who found improvement was good-to-excellent in group B versus group A. Concerning patients' satisfaction, 108 patients (58.7\%) were very satisfied by the outcome, 64 patients (34.8\%) were satisfied and only 12 patients (6.5\%) were dissatisfied, also, with a significant difference between patients of both groups in favor of group B (Table 6).

\section{Discussion}

The present study aims to evaluate the outcome of classic laminectomy surgery alone versus laminectomy with fixation surgery in patients with lumbar canal stenosis regarding the improvement of pain and function.

The present study reported more than 50\% improvement of pain and disability regarding NRS pain and ODI scores throughout the period of follow-up compared to preoperative scores in both groups with

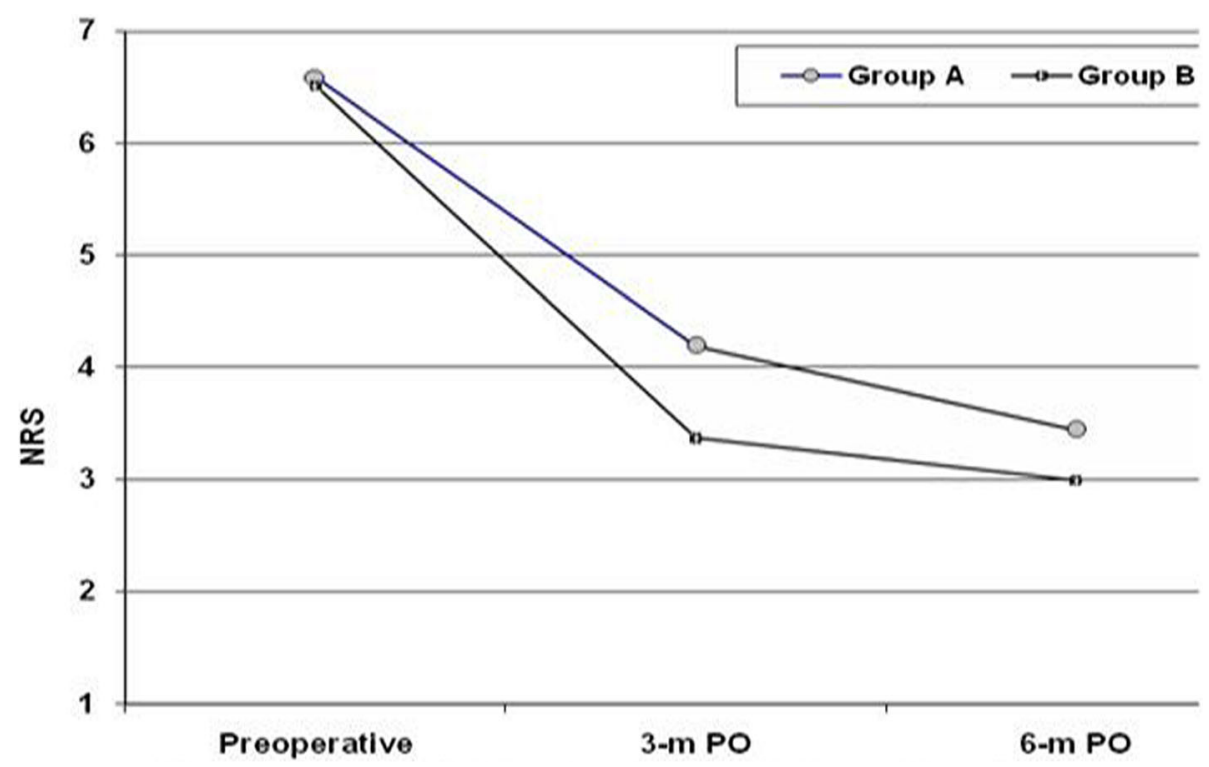

Fig. 5 Mean NRS determined at score at 3 and 6 months post-operative in patients of both groups compared to pre-operative score 


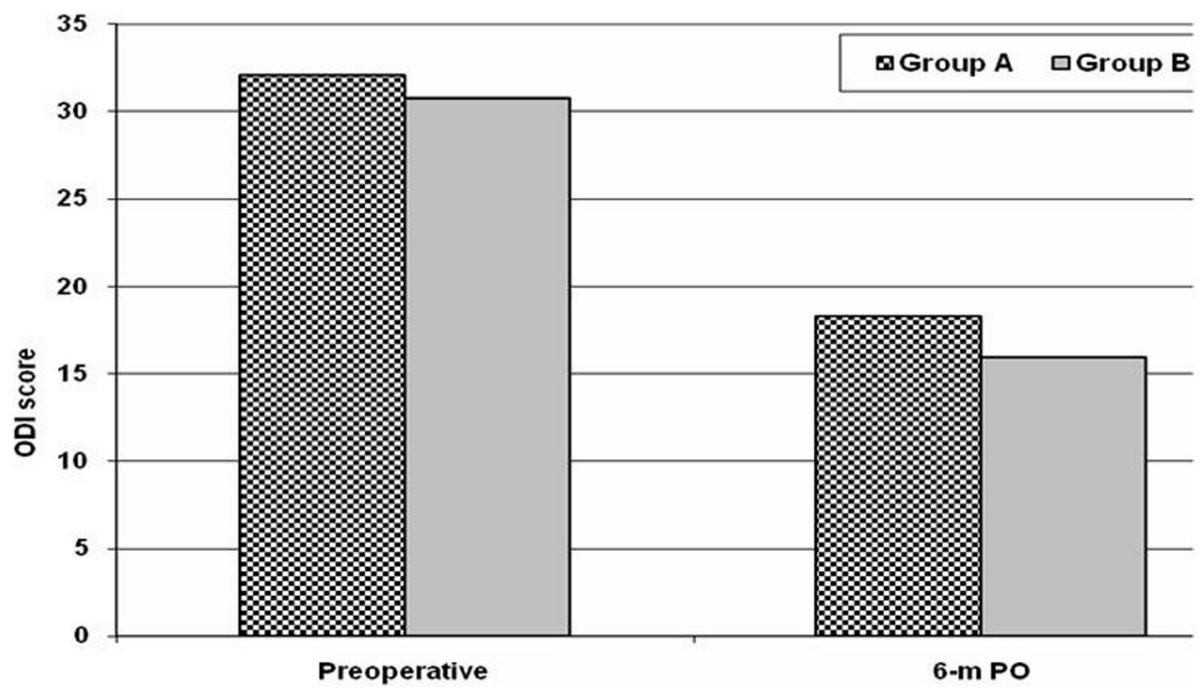

Fig. 6 Mean ODI score at 6 months post-operative in patients of both groups compared to pre-operative score

more improvement of the second group (group B). This comes in agreement with Wang et al. [17] and Liao et al. [18] and their colleague as they used laminectomy and interlaminar lumbar-instrumented fusion for lumbar spinal stenosis and reported a significant improvement of pain and disability regarding VAS and ODI scores throughout the period of follow-up compared to preoperative scores.

The present study reported the significantly high success rate regarding patients satisfaction as $58.7 \%$ of patients were very satisfied by the outcome, $34.8 \%$ were satisfied, and only $6.5 \%$ of patients were dissatisfied, with a higher success rate for patients of group B compared to those of group A. This is corresponding to Liao et al. [18] and his colleague as they retrospectively studied 181 patients who underwent posterior decompression and instrumentation with posterolateral fusion for degenerative lumbar diseases with spinal stenosis and reported $86 \%$ of patients exhibited good or excellent result.

Sun et al. [19] also reported the satisfactory clinical and radiological outcomes with the use of multisegmental transforaminal enlarged decompression plus lumbar fusion for the treatment of multilevel lumbar spinal canal stenosis and found that this technique can reduce surgically induced instability.

Our results reported that the effectiveness of procedure including fixation using transpedicular screws with posterior decompression was also manifested as significantly higher improvement of muscle power of dorsiflexors and extensor halucies longus muscles regarding Odom's scoring with

Table 5 Pain NRS and ODI scoring of studied patients at 3- and 6-month PO

\begin{tabular}{|c|c|c|c|c|c|c|}
\hline \multicolumn{4}{|l|}{ Parameter } & \multirow{2}{*}{$\begin{array}{l}\text { Group A } \\
(n=92)\end{array}$} & \multirow{2}{*}{$\begin{array}{l}\text { Group B } \\
(\mathrm{n}=92)\end{array}$} & \multirow{3}{*}{$\begin{array}{l}P \\
\text { value } \\
0.936\end{array}$} \\
\hline \multirow{7}{*}{ NRS score } & \multirow{4}{*}{ Score } & \multirow{2}{*}{\multicolumn{2}{|c|}{ Preoperative }} & & & \\
\hline & & & & $6.6 \pm 1.2$ & $6.5 \pm 1.3$ & \\
\hline & & \multicolumn{2}{|c|}{ At 3-month follow-up } & $4.2 \pm 1.9^{a}$ & $3.4 \pm 1.6^{a}$ & 0.0042 \\
\hline & & \multicolumn{2}{|c|}{ At 6-month follow-up } & $3.4 \pm 1^{\mathrm{ab}}$ & $3 \pm 1.3^{\mathrm{a}}$ & 0.0048 \\
\hline & \multirow[t]{3}{*}{ Percentage of decrease } & \multirow[t]{2}{*}{ Frequency } & $\geq 50 \%$ & $54(58.7 \%)$ & $69(75 \%)$ & \multirow[t]{2}{*}{0.0188} \\
\hline & & & $<50 \%$ & $38(41.3 \%)$ & $23(25 \%)$ & \\
\hline & & \multicolumn{2}{|c|}{ Mean percentage } & $47.4 \pm 13.1$ & $54.3 \pm 16.6$ & 0.002 \\
\hline \multirow[t]{5}{*}{ ODI score } & Preoperative & & & $32 \pm 5$ & $30.8 \pm 4.6$ & 0.063 \\
\hline & At end of follow-up & & & $18.3 \pm 3.9$ & $15.9 \pm 3$ & 0.0001 \\
\hline & \multirow[t]{3}{*}{ Percentage of decrease } & \multirow[t]{2}{*}{ Frequency } & $\geq 50 \%$ & $29(31.5 \%)$ & $48(52.2 \%)$ & \multirow[t]{2}{*}{0.0045} \\
\hline & & & $<50 \%$ & $63(68.5 \%)$ & $44(47.8 \%)$ & \\
\hline & & \multicolumn{2}{|c|}{ Mean percentage } & $41.7 \pm 13.6$ & $47.2 \pm 12.5$ & 0.0019 \\
\hline
\end{tabular}

This table shows that the success rate presented as the frequency of patients developed $\geq 50 \%$ reduction of both pain and ODI scores were significantly higher in group B versus group A 


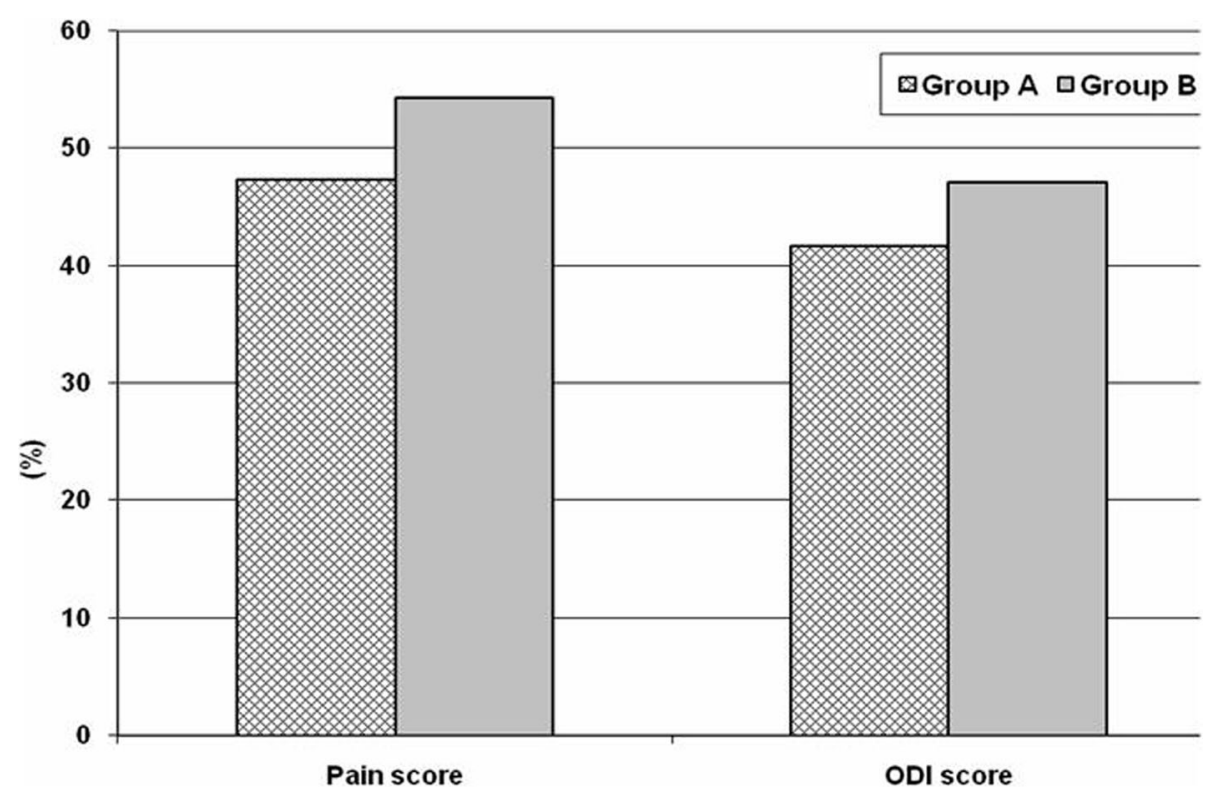

Fig. 7 Mean percentage of improvement of pain and ODI score at 6 months post-operative in patients of both groups

more improvement of group B and the significant reduction of the use of pain medications with subsequent higher satisfaction rates throughout the period of follow-up compared to preoperative parameters.

This comes in agreement with Zeng et al. [20] and his colleague as they found that unilateral pedicle screw fixation combined with contralateral percutaneous translaminar facet screw fixation and lumbar interbody fusion is a good choice for the treatment of spinal canal stenosis regarding improvement of muscle power and the reduction of the use of analgesics.

The applied procedures for both groups were safe with acceptable operative time, blood loss, and short postoperative hospital stay with non-significant differences

Table 6 Postoperative data of studied patients

\begin{tabular}{|c|c|c|c|c|}
\hline \multicolumn{2}{|l|}{ Parameter scores } & \multirow{2}{*}{$\begin{array}{l}\text { Group A } \\
(n=92)\end{array}$} & \multirow{2}{*}{$\begin{array}{l}\text { Group B } \\
(n=92) \\
\end{array}$} & \multirow{2}{*}{$\begin{array}{l}P \\
\text { value }\end{array}$} \\
\hline \multirow{6}{*}{ PO analgesic medications } & & & & \\
\hline & 0 & $23(25 \%)$ & $39(42.4 \%)$ & 0.095 \\
\hline & 1 & $47(51.1 \%)$ & $36(39.1 \%)$ & \\
\hline & 2 & $20(21.7 \%)$ & $16(17.4 \%)$ & \\
\hline & 3 & $2(2.2 \%)$ & $1(1.1 \%)$ & \\
\hline & Total & $1 \pm 0.7$ & $0.8 \pm 0.7$ & 0.034 \\
\hline \multirow[t]{3}{*}{ EHL muscle strength testing } & Preoperative & $2 \pm 0.7$ & $2 \pm 0.8$ & 0.897 \\
\hline & At 6-month follow-up & $2.9 \pm 0.6$ & $3.3 \pm 1$ & 0.001 \\
\hline & Percentage of change & $65.2 \pm 51.7$ & $77 \pm 49.6$ & 0.116 \\
\hline \multirow[t]{4}{*}{ Odom's criteria } & Excellent & $21(22.8 \%)$ & $29(31.5 \%)$ & 0.046 \\
\hline & Good & $46(54 \%)$ & $52(56.6 \%)$ & \\
\hline & Fair & $18(15.6 \%)$ & $6(6.5 \%)$ & \\
\hline & Poor & $7(7.6 \%)$ & $5(5.4 \%)$ & \\
\hline \multirow[t]{3}{*}{ Satisfaction scoring } & Very satisfied & 46 (49.9\%) & $62(67.4 \%)$ & 0.031 \\
\hline & Satisfied & 37 (40.2\%) & 27 (29.3\%) & \\
\hline & Dissatisfied & $9(9.9 \%)$ & $3(3.3 \%)$ & \\
\hline
\end{tabular}

This table shows a significant improvement of patients regarding EHL muscle strength testing in comparison to their preoperative data with significantly superior outcome among patients of group B compared to group A. there was a significantly higher frequency of patients who found improvement was good-to-excellent in group B versus group A regarding patients' evaluation of improvement according to Odom's criteria. Concerning patients' satisfaction, there was a significant difference between patients of both groups in favor of group B 
between both groups. In line with safety of the applied procedures, Munting et al. [21] compared patient outcomes and complication rates after different decompression techniques or instrumented fusion in lumbar spinal stenosis and found laminectomy with instrumented fusion was significantly more beneficial than laminotomy, hemilaminectomy, and laminectomy regarding leg pain improvement with non-significant differences regarding operative and short-term postoperative data.

\section{Conclusion}

The present study concluded the efficacy and safety of the applied procedure including wide laminectomy, foraminotomy, discectomy, and medial facetectomy with spinal fixation using transpedicular screws for management of patients with spinal canal stenosis. However, a multicenter comparative study with long-term follow-up is recommended to establish the obtained results.

\section{Abbreviations}

LCS: Lumbar canal stenosis; CCS: Cervical canal stenosis; NAISD: Non-steroidal anti-inflammatory drugs; NRS: Numeric rating scale; ODI: Oswestry disability index; Rt: Right; Lt: Left; EHL: Extensor hallucis longus; AP: Antero-posterior; $\mathrm{CT}$ : Computerized tomography; MRI: Magnetic resonance imaging; X2: Chisquare test; PACU: Post-anesthetic care unit; PO: Postoperative; M: Month

\section{Acknowledgements}

We thank all participants and assistants in completing the work.

\section{Authors' contributions}

Designed the study: MAET, SEAE, MAH, Acquired the study data: DSS, MAET, and YBES. Contributed to the materials or analysis tools: MAET, YBES, SEAE, $\mathrm{MAH}$. Wrote the manuscript: DSS, MAET. All authors read and approved the final manuscript.

\section{Funding}

Not applicable.

\section{Availability of data and materials}

All data generated or analyzed during this study are included in this published article (and its supplementary information files).

\section{Ethics approval and consent to participate}

The research protocol was approved by the ethical committee in the Faculty of Medicine Menoufyia University in its monthly session. An informed written consent was obtained from each patient.

\section{Consent for publication}

The consent for publication was obtained from all persons sharing in the study. All presentations of case reports had have consent for publication.

\section{Competing interests}

The authors declare that they have no competing interests in this article.

\section{Author details}

${ }^{1}$ Neurosurgery, Faculty of Medicine, Menoufyia University, Shebeen El-Kom-Menoufia, Egypt. ${ }^{2}$ Physical Medicine, Rheumatology and Rehabilitation, Faculty of Medicine, Menoufyia University, Shebeen El-Kom-Menoufia, Egypt.
Received: 7 September 2019 Accepted: 9 June 2020

Published online: 13 July 2020

\section{References}

1. Ruetten S, Komp M. The trend towards full-endoscopic decompression: current possibilities and limitations in disc herniation and spinal stenosis. Orthopade. 2019;48(1):69-76.

2. Hart R. Topping phenomenon with recurrent spinal stenosis and epidural fibrosis prevented with oxidized cellulose - a case report. Acta Med (Hradec Kralove). 2018;61(2):69-73.

3. Splettstößer A, Khan MF, Zimmermann B, Vogl TJ, Ackermann H, Middendorp M, Maataoui A. Correlation of lumbar lateral recess stenosis in magnetic resonance imaging and clinical symptoms. World J Radiol. 2017; 9(5):223-9.

4. Cowley P. Neuroimaging of spinal canal stenosis. MagnReson Imaging Clin N Am. 2016:24(3):523-39.

5. Benditz A, Grifka J. Lumbar spinal stenosis: from the diagnosis to the correct treatment. Orthopade. 2019. https://doi.org/10.1007/s00132-018-03685-3.

6. Hiratsuka S, Takahata M, Hojo Y, Kajino T, Hisada Y, Iwata A, Yamada K, Iwasaki N. Increased risk of symptomatic progression of instability following decompression for lumbar canal stenosis in patients receiving chronic glucocorticoids therapy. J Orthop Sci. 2019;24(1):14-8.

7. Soliman HM. Irrigation endoscopic decompressive laminotomy. A new endoscopic approach for spinal stenosis decompression. Spine J. 2015; 15(10):2282-9.

8. Shi SY, Huang YS, Hao DJ. Therapeutic progress in lumbar spinal stenosis. Zhongguo Gu Shang. 2017;30(5):484-8.

9. Fairbank JC, Couper J, Davies JB, O'Brien JP. The Oswestry low back pain disability questionnaire. Physiotherapy. 1980;66(8):271-3.

10. Williamson A, Hoggart B. Pain: a review of three commonly used pain rating scales. J Clin Nurs. 2005:14(7):798-804

11. Fairbank JC, Pynsent PB. The Oswestry disability index. Spine. 2000;25(22): 2940-53.

12. Davidson M, Keating J. A comparison of five low back disability questionnaires: reliability and responsiveness. Phys Ther. 2002:82:8-24

13. Manchikanti L, Singh V, Falco FJE, Cash KA, Pampati V, Fellows B. Comparative effectiveness of a one-year follow-up of thoracic medial branch blocks in management of chronic thoracic pain: a randomized double-blind active controlled trial. Pain Physician. 2010;13:535-48.

14. van Brakel WH, Nicholls PG, Das L, Barkataki P, Suneetha SK, Jadhav RS, Maddali P, Lockwood DN, Wilder-Smith E, Desikan KV. The INFIR cohort study: investigating prediction, detection and pathogenesis of neuropathy and reactions in leprosy. Methods and baseline results of a cohort of multibacillary leprosy patients in north India. Lepr Rev. 2005:76(1):14-34

15. Roberts $A E$, Nicholls $P G$, Maddali $P$, Van Brakel WH. Ensuring inter-tester reliability of voluntary muscle and monofilament sensory testing in the INFIR. Lepr Rev. 2007;78:122-30.

16. Odom GL. Neurosurgical care of the severely injured patient. J Am Med Assoc. 1958;168(16):2087-90.

17. Wang L, Liu C, Li GQ, Tian JW. Transforaminal lumbar interbody fusion in the treatment of lumbar intervertebral disc herniation with lumbar instability. Zhonghua Yi Xue Za Zhi. 2012;92(39):2781-4.

18. Liao JC, Fan KF, Chen WJ, Chen LH. Posterior instrumentation with transpedicular calcium sulphate graft for thoracolumbar burst fracture. Int Orthop. 2009:33(6):1669-75.

19. Sun C, Tian WJ, Liu HX, Guan PG. Outcomes of multisegmental transforaminal enlarged decompression plus posterior pedicle screw fixation for multilevel lumbar spinal canal stenosis associated with lumbar instability. Int J Surg. 2018:50:72-8.

20. Zeng ZL, Zhu R, Wu YC, Zuo W, Yu Y, Wang JJ, Cheng LM. Effect of graded facetectomy on lumbar biomechanics. J HealthcEng. 2017;2017:7981513.

21. Munting E, Röder C, Sobottke R, Dietrich D, Aghayev E. Spine Tango Contributors: Patient outcomes after laminotomy, hemilaminectomy, laminectomy and laminectomy with instrumented fusion for spinal canal stenosis: a propensity score-based study from the Spine Tango registry. Eur Spine J. 2015:24(2):358-68.

\section{Publisher's Note}

Springer Nature remains neutral with regard to jurisdictional claims in published maps and institutional affiliations. 